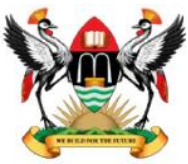

East African School of Higher Education Studies \& Developmen

\title{
Delegation and Staff Commitment in the School of Finance and Banking, Kigali, Rwanda
}

\author{
Pascal Kiiza ${ }^{1}$, Epiphany Odubuker Picho ${ }^{1, *}$ \\ ${ }^{1}$ Muni University [* Corresponding author: epipicho@gmail.com]
}

\begin{abstract}
The purpose of the study was to investigate the relationship between Delegation of Authority and Staff Commitment in the School of Finance and Banking in Kigali Rwanda. A cross-sectional survey design was used with the target sample size of 97 out of 130 parent population. The total number of questionnaires that were filled and returned was 78, giving a high response rate of 80.5 percent. Due to the heterogeneous nature of the population, the researchers used stratified sampling and random sampling. Descriptive analysis involving frequencies, percentages and Pearson Product Moment Correlation Coefficient for inferential statistics were carried out. The correlation between the two variables was weak at .287 , and significant at .011 value. The results were linearly correlated and this implies that staff commitment is positively correlated with Delegation of Authority; whenever employees are delegated authority, they are likely to be more committed and vice versa.
\end{abstract}

Keywords: Delegation; Authority; Staff Commitment

\section{$1 \quad$ Introduction}

The Government of Rwanda has various objectives that act as the point of focus in its policy formulation and implementation. Among these is that of devising and implanting policies that promote the welfare of its citizenry. It was in pursuit of this objective that the School of Finance and Banking (SFB), a public institution of higher learning, was established in June 2002 and took up its training mandate in 2004, offering Masters in Business Administration (MBA) with specializations in Banking, Finance, Project Management and Association of Chartered Certified Accountants (ACCA) programme, a professional course in accountancy. In addition, tailor-made short-courses and professional programmes were designed in various management disciplines to meet the changing needs of business leaders and managers. In 2005, a Cabinet meeting 
decided that the Management Faculty that was part of Kigali Institute of Technology (KIST) be transferred to the School of Finance and Banking (SFB) effective January 2006. Consequently, in addition to Master of Business Administration (MBA), SFB started offering Bachelor of Business Administration (BBA) programme in Accounting, Finance, Human Resources Management and Marketing specializations. Today, various undergraduate programmes and short- courses are being implemented to cater for the needs of Rwandan and regional labour market, transforming the SFB into an international business school.

According to National Council for Higher Education of Rwanda report on public higher institutions (NCHE, 2010), School of Finance and Banking was among the leading institutions where staff commitment was reported; this situation was worse during $2008 \& 2009$ academic years. No study, however, was conducted to determine the extent to which delegation practices has obstructed staff commitment in the SFB, a gap this study attempts to fill.

Conceptually, the term delegation was conceptualized as the actions by which a leader assigns part of his or her authority commensurate with the assigned task to a subordinate. While ultimate responsibility cannot be relinquished, delegation of authority carries with it the imposition of a measure of responsibility and the extent of the authority delegated must be clearly stated. Yukl (2002) discourses, delegation involves assignment of new responsibilities to employees and additional to carry them.

With regard to commitment, Pfeffer (1998) looks at this concept as the social and psychological processes whereby members of an organization develop and maintain an attachment to the organization. In other words, commitment occurs when the interests of an individual merge with the interests of an organization, resulting in the creation of identifications based on those interests. This study, however, adopted Meyer and Allen's (1991) conceptualization of commitment as a form of psychological attachment to an employing organization. While it is imperative that efforts are made to elicit staff commitment, it is equally imperative that the leaders of education institutions demonstrate the practices necessary to be successful leaders.

Contextually, many institutions claim, their employees are their greatest asset and agents of their success; the notion of staff commitment is often overlooked yet it is of great importance to organizational functioning. Given the fact that institutional leaders usually work in unpredictable situations where they often experience stress and frustrations, the question is: what factors prevent their employees from being committed to the goals and values of their organizations. In many developing countries, Rwanda inclusive, initiatives for improving education systems have often been short-lived. Individuals implementing such initiatives seem to lack an understanding of effective leadership practices, ultimately resulting into lack of satisfactory loyalty from subordinates. 
According to NCHE for Rwanda (2010) report on public higher institutions, School of Finance and Banking was among the leading institutions where staff commitment reported to be low. A study by Public Service Commission (2010) of Rwanda found that 68 percent of public sector employee had changed institutions more than once between $2008 \& 2009$. One of the main causes of low staff commitment was poor management of human resources, according to this report. But as Snowden \& Gorton (2002) affirm, for improvement efforts to be realized, a leader is key to providing the leadership necessary for such efforts to be met with success.

It is believed that leaders must, among other things, put in place adequate mechanisms to empower their subordinates for organizational commitment to occur. Various strategies are used to induce employees to embrace the values and goals of the organization; With particular reference to the School of Financing and Banking, hardly had there been a single study conducted to find out whether leadership practices have had an influence on staff commitment; hence, this study aimed at determining the extent to which delegation of authority, as one of the leadership practices mechanism, affect staff commitment in the School of Financing and Banking - Rwanda.

\subsection{Statement of the Problem}

Like other organizations, educational institutions have long recognized human capital as a competitive advantage for their effectiveness. The School of Finance and Banking - Kigali as a creature of the Rwandan Government was intended to create and build human capital to spur growth and development of the country and boost up the labour market in the region through provision of a highly trained, skilled and committed work force. The NCHE (2010) report on public higher institutions, revealed that School of Finance and Banking was among the leading institutions where staff commitment was low; this situation was worse during 2008 and 2009 academic years. To date, no empirical study has been conducted to establish the explaining variables for the above predicament but the researchers hunched leadership practices to be exerting a significant influence on staff commitment. Accordingly, this study was glinted to inquire about the relationship between delegation of authority as a leadership practice and employee commitment in the School of Finance and Banking, Kigali - Rwanda.

\subsection{Scope}

Geographically, the study was carried out in the School of Finance and Banking-Kigali, which is one of the higher public institutions in Rwanda. It was legally established under School of Finance and Banking statute law No. 
21/2002. It is located at Mburabuturo in central Kigali City in Kicukiro District. The content scope of the study focused on delegation of authority as a leadership practice and staff commitment.

\subsection{Conceptual Framework}

The independent variable (delegation of authority) is a leadership practice while the dependent variable is staff commitment. The researchers postulates that in organizations where there is effective delegation of authority, the level of commitment of staff to their jobs is likely to be high. The extraneous variables, which inter alia, include finances that are likely to compete with the independent variable to explain the dependent variable are held constant to control their influence in explaining the variability in the dependent variable.

\section{$2 \quad$ Methodology}

This section highlights the research design, target population, sample and sampling techniques that were used in data collection. It also presents the instruments used in data collection, quality control techniques, research procedure and analysis of data.

The research used a cross sectional survey design. This enabled the researchers to collect a lot of information from a number of respondents at one point in time and its results can be generalized to a larger population within defined boundaries (Amin, 2005). The study employed both quantitative and qualitative research paradigms. The institution had a total of 130 employees of which 70 comprised the teaching staff while 60 were the non-teaching staff.

From a parent population of 130 a sample of size of 97 was determined by the use of Krejcie \& Morgan (1970) as cited by Amin (2005). The total number of questionnaires that were completely filled and returned was 78 respondents; this gave a high response rate of 80.5 percent. Due to the heterogeneous nature of the population, the researcher used stratified sampling; proportionate sample from each sub-group was obtained in order to ensure that all groups were fairly represented in the study. Random sampling was then used because of the advantage it has in avoiding bias in that each member in the target population had an equal opportunity of being chosen (Amin, 2005).

In this study, the researcher used both primary and secondary methods of data collection. For the case of primary methods of data collection, field data was collected with the help of a self-administered questionnaire and an interview guide as explained below.

A questionnaire was used in collecting data pertaining to the objectives of the study. The literature review revealed that most of organization commitment 
researches have used questionnaires as an instrumental of data collection. For this study, the questionnaire survey was selected because it was specifically developed to reach several respondents at the same time. This made it ideal to explore the correlation between leadership practices and staff commitment in an academic setting. The questionnaire included statements that elicited information under the three attributes of leadership practices namely: delegation of authority, effective communication and participation in decision making. In the same way, items on the dependent variable (staff commitment) were also formulated. Specifically, this research used a closed-ended questionnaire based on a five point Likert scale responses that ranged from strongly disagree to strongly agree with codes ranging from 1 to 5 . Subsequently, overall scores for each respondent were computed from the results of the raw data by obtaining the average of all valid responses intended to obtain each respondent's opinion in relation to each of the three independent variables and the dependent variable ranging from 1.0 to 5.0. The closed-ended questionnaire was particularly preferred because they are easy to quantify and analyse (Amin, 2005).

The researcher carried out interviews with some administrators of the SFB. According to Trochim (1996) interviews are useful in data collection because they contain probing questions that allow flexibility in asking and obtaining indepth information from respondents. This allowed the researcher to triangulate the quantitative findings of the staff with the qualitative data from the administrators.

In case of secondary data, the study begun with a review of relevant literature sources that had been published in the same field such as research reports, journals and other relevant library materials.

Data quality was ensured by checking the validity and reliability of the questionnaire.

Critical validation of the instrument was done by the supervisors who rated the degree to which the instrument actually measures the traits for which it was designed to measure (Amin, 2005) as per the study objectives. The researcher then computed the validity coefficient using the Content Validity Index (CVI). This was established by the proportion of number of items declared valid over the total number of items. The CVI of 0.7 indicated that the instrument was valid since it was above the minimum recommended value of 0.7 (Amin 2005).

The reliability coefficient was computed using Cronbach's alpha formula coefficient. This was done in order to assess the reliability of the questionnaire. This method was deemed appropriate because most of the items in the questionnaire were closed ended and since Cronbach's alpha coefficient gives the average correlation of all items in the questionnaire, the researcher considered it more suitable to compute the overall reliability of the instrument. The average correlation between the items in the questionnaire was .894 which 
was above 0.7 the normal degree for accepting reliability of instruments (Nunnally \& Bernstein, 1994) implying that the questionnaire was reliable.

Data was coded and entered into computer using the Statistical Package for Social Sciences (SPSS) for analysis. Descriptive analysis was done involving the presentation of findings in form of frequency tables and graphs with their respective percentages. Statistical analysis involved the use of the Pearson product moment correlation coefficient for inferential statistics. As for qualitative data, the researcher used a critical assessment of each response, examining it using thematic interpretation in accordance with the study objectives. These were presented qualitatively in form of quotations.

\section{$3 \quad$ Findings}

The study aimed at establishing the relationship between delegation of authority and staff commitment. In the questionnaire six statements that translated this objective into specific items were formulated to elicit the responses of the staff on how they perceived the way delegation of authority was practiced in the institution. For each respondent, the responses on these items were summed up to generate an overall score of staff perceptions on delegation of authority. This index was later correlated with staff commitment to determine whether relationship exists between the two variables. The findings are shown in Table 1.

Table 1: Delegation of authority

\begin{tabular}{llllll}
\hline Item & SD & D & N & A & SA \\
\hline I feel free to open my & $7(9 \%)$ & 18 & 15 & 29 & 9 \\
heart to my boss & & $(23.1 \%)$ & $(19.2 \%)$ & $(37.2 \%)$ & $(11.5 \%)$ \\
$\begin{array}{l}\text { My supervisor allows me } \\
\text { do some work on his }\end{array}$ & 8 & 15 & 20 & 27 & 8 \\
$\begin{array}{l}\text { behalf } \\
\text { I decide on how best to do }\end{array}$ & 1 & 8 & 10 & 34 & 25 \\
$\begin{array}{l}\text { my work } \\
\text { I feel personally }\end{array}$ & $(1.3 \%)$ & $(10.3 \%)$ & $(12.8 \%)$ & $(43.6 \%)$ & $(32.1 \%)$ \\
responsible for the & $(1.3 \%)$ & 3 & 10 & 38 & 24 \\
$\begin{array}{l}\text { outcomes of my work } \\
\text { My boss does not interfere }\end{array}$ & 5 & $(3.9 \%)$ & $(13.2 \%)$ & $(50.0 \%)$ & $(31.6 \%)$ \\
$\begin{array}{l}\text { with my work } \\
\text { I have control of the }\end{array}$ & $(6.4 \%)$ & $(25.6 \%)$ & $(24.4 \%)$ & $(32.1 \%)$ & $(11.5 \%)$ \\
activities in this institution & $(9.1 \%)$ & 27 & 23 & 15 & 5 \\
\hline
\end{tabular}

In Table 1, apart from the sixth statement where most of the respondents either expressed negative sentiments $35(44.2 \%)$ or taking a neutral position 23 
(29.9\%) on whether they had control over the activities in their institution, the rest of the statements received a positive rating. In particular, according to the pattern of the responses, most of the staff asserted that they always felt free to open their hearts to their bosses. This in one way helps in creating a cordial relationship and a two way communication between the subordinates and their bosses. This collegial relationship is not only important for the supervisors to develop trust in their subordinates but it also avails the bosses the opportunity to entrust some of their duties to their subordinates. Indeed, in support this contention it was indicated by a considerable number of the participants in the study that their supervisors allowed them to do some work on behalf of their bosses. Similarly, the qualitative responses indicated that subordinates were always given chances to make decision on behalf of their supervisor. Some of the examples where subordinate represented their immediate supervisors included: Senate meetings, executive and education meetings. In this regard, Interviewee 2 from the finance unit reported:

I assign them some duties to perform on my behalf like attending meetings, responding students' queries etc.

In the same vein, whenever a member of staff was allowed to do some work on behalf of his/her boss, in carrying out duties, most of them maintained that they always had the liberty to decide on how best to do their work implying that they were always independent. As a result of this independence, well knowing that they were accountable for their actions, employees mentioned that they always tried their level best to diligently perform their duties to the expectations of their bosses because at the end of the day, a person to whom authority was delegated was solely responsible for the outcomes of his/her action as indicated by $62(81.6 \%)$ respondents. Interview respondents were asked to give examples where their subordinate represented them and one of the striking finding from interviewee 5 from the Human Resource and Administration indicated that they always asked the former to represent them particularly in those areas where the supervisors had less expertise than the subordinates.

To demonstrate that once authority was delegated to them they became independent, a fairly large number of the interviewed staff 34 (43.6\%) reported that their bosses hardly interfered with their work. This implies that the role of the bosses was to supervise, counsel and guide the subordinates as to what would be the best way to execute their duties in case of any deviation from the established procedures. The different circumstances under which supervisors gave chances to their subordinates to make decision on their behalf included situations in which the former was absent and a decision had to be taken there and then. Under such circumstances delegation of authority was seen as very important as seen in the following narrative excerpts. 
I allow my subordinates to participate in different meetings and trainings on my behalf. Interviewee 5 (from the Research and Consultancy Unit)

"I allow my subordinate to represent me in training and meetings and when I am on my annual leave, when am sick or when am attending to some other official duties. In such cases, I assign my subordinate to act on my behalf". Interviewee 6(from the Finance Unit)

I normally call my staff for a departmental meeting from which they are given the opportunity to freely express their views and opinions. I subsequently forward their proposals in executive meetings. Interviewee 6 (from the Finance Unit)

Having obtained the responses from both questionnaires and interviews, it was important to establish whether the ratings on delegation of authority had any association with the responses on staff commitment. This hypothesis was tested using a Pearson correlation efficient and the results are given in Table 2.

Table 2: Correlation between delegation of authority and staff commitment

\begin{tabular}{llll}
\hline & & Delegation of authority & Staff Commitment \\
\hline Delegation of & Pearson Correlation & 1 & $.287\left(^{*}\right)$ \\
authority & Sig. (2-tailed) & & .011 \\
& $\mathrm{~N}$ & 78 & 78 \\
Staff & Pearson Correlation & $.287\left(^{*}\right)$ & 1 \\
Commitment & Sig. (2-tailed) & .011 & \\
& $\mathrm{~N}$ & 78 & 78 \\
\hline
\end{tabular}

${ }^{* *}$ Correlation is significant at the 0.05 level (2-tailed).

The summary statistics of the correlation in Table 2 show the computed value of the relationship between the two variables equal to 0.287 and significant at $0.05(\mathrm{P}<0.05)$. The findings therefore led the researcher to reject the null hypothesis in favour of the research alternative or research hypothesis that delegation of authority significantly relates to staff commitment. In other words, when leaders in the School of Finance and Banking in Kigali relinquish some of their powers to their subordinates, this will significantly raise the latter's level of commitment to the institution. 


\section{Discussion, Conclusions and Recommendations}

This section entails the discussion of the findings in relation to the research objectives that guided this study. Following the discussion are the conclusions, recommendations and areas for further research.

In the third and final objective, the results revealed that in addition to effective communication and participation in decision making, delegation was related to staff commitment. This was given by the value of the correlation equal to .287 with a sig-value of 0.011 . This indicates that in the SFB, staff commitment of individuals was positively enhanced by delegation. The results further align with Darjan \& Milan (2004) whose results revealed that delegation of authority to staff contributes to employees' allegiance to organizational goals and values. Similarly, the findings render credence to one of the earlier studies such as Brewer (1996) who demonstrated that delegation of authority as one of the important factors in shaping organizational commitment. Also, Jermies \& Berkes (1979; as cited in Mathieu \& Zajac, 1990) report similar findings that delegation of authority to subordinates increases the level of commitment among staff. It is in this regard that Knouse and Strutton (1996) points out that management should delegate to sales people the authority needed to make local decisions about pricing, delivery, and service. This is because effective delegation helps supervisors to pay close attention to employees to strengthen them (Muir, 1995).

In light of the findings, future research may need to examine the relative utility of the self-concept and the job characteristics as mechanisms through which delegation influences employee work outcomes. Because delegation motivates employees to behave in ways and/or hold attitudes that are consistent with their positive self-image within the SFB. From a managerial perspective, administrators in the SFB cannot be experts in all fields. In such situations, the decision maker delegates full or partial responsibility of decision making for a particular area of concern, to the expert on the team for best management outcomes. Advantages of this type of decision making process makes the group members feel engaged in the process, more motivated and creative.

Delegation of authority motivates a subordinate to perform the tasks with dedication and commitment. When authority is delegated, the subordinate knows that his superior has placed faith and trust in him. Managers who delegate effectively also receive several personal benefits; most importantly, they have more time to do their own jobs when they assign tasks to others. Given the hectic nature of managerial work, time is a precious commodity. Effective delegation frees the manager to focus on managerial tasks such as planning and control. Managers also benefit from the development of subordinates' skills. With a more highly skilled workforce, they have more 
flexibility in making assignments and are more efficient decision makers. Managers who develop their workforce are also likely to have high personal power with their staff and to be highly valued by their organization.

With delegation, every member of staff expected to show increased commitment to the organization and in this context the SFB. To achieve this, the behaviour of the staff is very important. Their behaviour is influenced by the environment in which they find themselves. If they are not given opportunities to utilize all of their skills, then the employer may never have the benefit of their total performance. However, improper delegation can cause a host of problems, primary of which is an incorrectly completed task, which may hurt the overall productivity of the organization. Thus, the process of delegation is as critical as the planning, because a poor process can reduce the effectiveness of the delegation in several ways. First, it can lower the worker's motivation to perform the task. A qualified worker who is not motivated to complete the assignment is not likely to produce the desired results. Second, lack of proper communication of standards for the task may lead to less than desirable outcomes. Finally, the delegation process may create some artificial barriers or fail to eliminate others barriers to performance. The failure to share information and discuss real or perceived problems can reduce efficiency and may lead to failure.

Effective leadership practices are those approaches that bring about quality awareness in all organizational processes. In this study, it was envisaged that for staff commitment to occur, the leadership of the SFB should among other factors improve their leadership. Specifically, the findings necessitated the rejection of the null hypotheses. Consequently, the rejection of the null hypotheses implied that there was reasonable proof to believe there was a significant relationship between the three basic leadership practices and staff commitment. Therefore, following the research findings and subsequent discussion, the following conclusions were made. There is a positive relationship between delegation of authority and staff commitment in the School of Finance and Banking in Kigali

From the results of the investigation, it was evident that leaders in the SFB should lay much emphasis is on their leadership practices in order to elicit their staff commitment. As far as the findings of this study are concerned, the following are the suggested recommendations to achieve the loyalty and devotion of the staff to their work and the entire institution as a whole.

It is also important for managers in the SFB to delegate some of their authority to their subordinates. This will not only free managers from focusing on managerial tasks such as planning and control but will also go a long way in benefiting from the development of subordinates' skills. But while delegating decision making to their staff, administrators in the SFB should provide the necessary support to the staff in form of coaching, guiding and advising them. 
In all, the school must become a learning organisation in which the staff are assisted to persevere and eventually succeed.

\section{References}

Amin, M. E. (2005). Social Science Research: Conception, Methodology and Analysis. Kampala. Makerere University Printery.

Brewer, A.M. (1996). Developing commitment between managers and employees. Journal of Managerial Psychology, 11(4), 24-34.

Darjan, GC and Milan, P (2004). Org

anizational Commitment in the Slovenian Police Force. http://www.ncjrs.gov/pdffiles1/nij/Mesko/207996.pdf

Jermies, J. and Berkes, L. (1979). Leader behaviour in a police command bureaucracy: A closer look at the quasi-military model. Administrative Science Quarterly, 24:1-23.

Knouse, S and Strutton, D. (2006). Sales force through managing empowerment, evaluation, reward and recognition processes. Journal of marketing. Pp. 24-36.

Krejcie, R.V. \& Morgan, D.W. (1970) Determining sample size for research activities. Educational and Psychological Measurements, 30, 607-610.

Meyer, J. P. and Allen, N. J. (1991). A three-component conceptualization of organizational commitment", Human Resource Management Review, 1 (1):61-89.

Muir, J. (1995), Effective management through delegation .Work Study, Volume 44, No.7, pp. 6-7.

National Council for Higher Education, (2010). Statistical Information on Higher Learning Institutions in Rwanda.

Nunnally, J. C. \& Bernstein, I. H. (1994). Psychometric Theory ( ${ }^{\text {rd }}$ ed.). New York: NY: McGraw- Hill Series in Psychology, McGraw-Hill, Inc., 264-265.

Pfeffer, J. (1998). Seven practices of successful organizations. California Management Review, 40 (2):96-123.

Public Service Commission, (2010). Baseline Survey on Causes of work conflicts Causes of Labour Mobility, Skills and Competencies. Kigali: Government of Rwanda.

Snowden, P. E., \& Gorton, R. A. (2002). School leadership and administration: Important concepts, case studies, \& simulations. Boston: McGraw Hill.

Trochim, D. (1996). The survey research: The research methods knowledge base. ww.trochim.human.cornell.edu/kb/survey.htm

Yukl, G. (2002). Leadership in organizations ( $5^{\text {th }}$ Ed.). NY: Prentice-Hall. 